\title{
ANÁLISE DA REDE GEOGRÁFICA NACIONAL DA INDÚSTRIA MISSIATO DE BEBIDAS LTDA
}

\section{ANALYSIS OF THE NATIONAL GEOGRAPHICAL NETWORK OF THE INDÚSTRIA MISSIATO DE BEBIDAS LTDA}

\author{
Francisco John Lennon Alves Paixão Lima', Maria das Graças de Lima' \\ ${ }^{1}$ Universidade Estadual de Maringá (UEM), Maringá, PR, Brasil
}

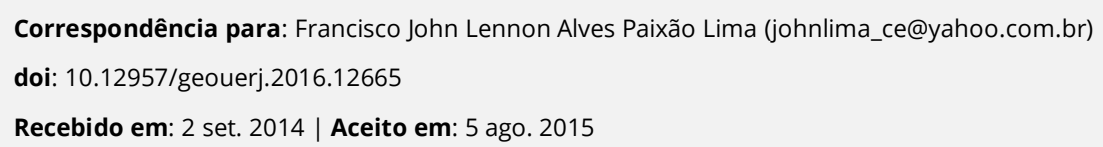

\section{RESUMO}

O presente artigo tem por finalidade analisar a rede geográfica nacional da Indústria Missiato de Bebidas Ltda. Para tal, foi realizada revisão bibliográfica, em especial dos estudos de Roberto L. Corrêa, Milton Santos e Tânia M. Fresca, pesquisa em sites e jornais digitais, bem como por contato por telefone, e-mail e ofício à referida indústria, na perspectiva de coleta de dados. A partir de então seguiu-se com análise, interpretação e problematização dos materiais colhidos, o que culminou maior clareza e tornou possível a produção deste trabalho. Conhecida pela cachaça "Jamel", a indústria hoje possui atividade em todos os estados do Brasil e no exterior, distribuindo uma gama variada de aguardente. Entretanto, apresenta um padrão de interação espacial em rede do tipo dendrítico, um arranjo de origem do período colonial, conforme Corrêa (2010, 2011), mas que se mostra eficiente às necessidades da indústria, particularmente de logística, bem como na produção e reprodução de capital, projetando-a como uma das principais produtoras em seu ramo no país. A indústria conduz ainda o fator proximidade como primordial em sua dinâmica e não apresenta interações espaciais multidirecionadas, que é característica do padrão de múltiplos circuitos.

Palavras-chave: Rede geográfica; Interações espaciais; Fluxo; Aguardente; Indústria Missiato.

\section{ABSTRACT}

This article aims to analyze the national geographic network of Indústria Missiato de Bebidas Ltda. For this matter, It was accomplished literature review, particularly through the studies of Roberto L. Corrêa, Milton Santos and Tânia M. Fresca, research on websites and digital newspapers, as contact by phone, email and draft letter to this industry, aiming to get information relevant to the research. Then it was followed with analysis, interpretation and problematization of collected materials, what led to greater clarity and has made possible the production of this work. Known for the alcoholic drink "Jamel", today the industry has its activity in all states of Brazil and abroad, distributing a wide range of alcoholic beverages. However, it has spatial interaction pattern at network of dendritic type, an arrangement of origin from colonial period, according to Corrêa (2010, 2011), but it shows effective to the industry's needs, particularly about logistics, such as production and reproduction of capital, projecting it as one of the leading producers in its branch in the country. The industry still leads the proximity factor as paramount in its dynamic and doesn't show multi-directions spatial interactions, which is standard feature of pattern of multiple circuits.

Keywords: Geographic network; Spatial interactions; Flux; Alcoholic beverages; Indústria Missiato.

\section{INTRODUÇÃO}

O presente artigo tem por objetivo analisar a rede geográfica da Indústria Missiato de Bebidas Ltda.

De início, foi realizada revisão bibliografia sobre o tema, pesquisa em sites e jornais digitais, bem como 
por telefone, e-mail e ofício à referida indústria, na perspectiva de coleta de dados. A partir de então, seguiu-se com análise e interpretação dos materiais colhidos.

O tema rede geográfica, assim como sua mais importante manifestação, a rede urbana (CORREA, 2011, p. 199), foi e continua sendo bastante discutido na atualidade, gerando uma variedade de trabalhos na temática. Com isso, foi possível construir o referencial teórico necessário a promoção deste artigo, tendo como foco principal os estudos de Roberto Lobato Corrêa, Milton Santos e Tânia Maria Fresca, todos articulados a rede geográfica.

Conhecida nacionalmente pela cachaça Jamel, a Indústria Missiato originou-se na década de 1950 no interior do estado de São Paulo, na cidade de Santa Rita do Passa Quatro. Hoje possui atividade em todo os estados do país, distribuindo uma gama variada de aguardente, desde a cachaça brasileira à vodkas e whiskys. A produção de aguardente da Missiato ocorre em duas unidades industriais, uma em Jandaia do Sul, no Paraná, e outra em Anápolis, no estado de Goiás, e destina-se a todos os estados do país. Sua venda é realizada a partir da atuação de representantes presentes em cada estado, sendo a distribuição derivada da unidade mais próxima e/ou dos centros de distribuição, um em Manaus-AM e outro em Porto Ferreira-SP. A indústria também exporta para alguns países da América do Sul, Europa e África, contudo o presente artigo trabalha apenas sua rede de atuação nacional.

Com o auxílio do levantamento teórico/bibliográfico e dos dados sobre a indústria, aplicando o princípio da analogia ao manuscrito produzido por Roberto L. Corrêa (2010) - intitulado esquemas gráficos geográficos - "Esquemas Geo(gráficos)" (onde o autor descreve sobre padrões de interação espacial em rede), somado à compreensão e à problematização de sua organização espacial, funcional e de logística chegou-se a conjuntura que a firmou como uma das principais produtoras de aguardente no mercado nacional, o que será exposto no decorrer deste trabalho. Sendo assim, tem-se o tipo de interação espacial em rede como central na análise.

Para compreensão do conceito de rede geográfica é fundamental que se entenda "redes", para assim chegar a sua geograficidade. De acordo com Santos (2002, p. 82), redes são "realidades concretas, 
formadas de pontos interligados que praticamente se espalham por todo o planeta, ainda que com densidade desigual, segundo os continentes e países." Estas possuem a fundamental característica, dentro do sistema capitalista, de condição da economia global e graças a essas redes, materiais e imateriais, a manutenção do modo de produção e a garantia de sua reprodução se asseguram (SANTOS, 2002).

Compreendido o conceito de "rede", Corrêa (2011, p. 200) vai mostrar que a rede geográfica corresponde a um "conjunto de localizações humanas articuladas entre si por meio de vias e fluxos". É, portanto, algo essencial ao entendimento do desenvolvimento do capitalismo na conjuntura mundial atual e por isso será acertada a devida atenção à um melhor detalhamento no tópico a seguir.

\section{DISCUTINDO A REDE GEOGRÁFICA}

A rede geográfica, como já apontada, é articulada por vias e fluxos, envolve poder, cooperação e relações entre várias esferas da sociedade (CORRÊA, 2011). Ela é uma construção social, logo humana, produto da sociedade, e geográfica por sua espacialidade, do contrário tratar-se-ia de um outro tipo de rede. Segue nas palavras do próprio autor:

[...] uma rede fluvial, constituída de nós ou confluências, e fluxos ou cursos de água, apresentase espacializada, originando uma bacia hidrográfica. Contudo, enquanto pura rede fluvial, regulada por leis da natureza, constitui-se em rede da natureza. Espacializada mas não-social, sem a presença humana. [...] Se a rede fluvial for objeto da ação humana, sendo transformada em rede de circulação fluvial, com portos e embarcações transportando pessoas e mercadorias, transforma-se em rede geográfica (CORRÊA, 2011, p. 202).

A compreensão geográfica da rede de atuação de uma empresa centra-se em sua espacialidade e em seu fator de articulação - ação humana - tratando-se, por exemplo, da circulação de bens e serviços, o que envolve capital, transporte, estradas, dados informacionais - tecnologia, técnica e informação.

As redes geográficas estão presentes em praticamente todos os lugares, não de forma homogênea, mas distribuídas conforme a demanda do capital (SANTOS, 2002). Segundo Fresca (2004, p.14), "a lógica capitalista de acumulação acaba por suscitar, por exemplo, valorização de certas localizações, em detrimento de outras". Essa lógica "perversa" aumenta as disparidades no planeta, partindo da divisão 
territorial do trabalho, mas é condição à manutenção do modo de produção, enriquecendo e priorizando de meio técnico científico determinadas áreas em detrimento de outras. Como apresenta Corrêa (2011, p. 202), na rede geográfica "há uma divisão territorial do poder e do trabalho, apresentando-se os seus centros tanto hierarquizados entre si como complementares entre si".

Ribeiro (1998, p. 63) coloca que, sob o capitalismo, uma rede urbana torna-se uma estratégia logística à acumulação de capital, tendo a cidade como expressão plena e dotada de meios técnicos científicos que permitem a expansão do mercado. Para as indústrias, não mais se faz necessário estarem próximas espacialmente da matéria prima, da mão de obra ou do próprio mercado consumidor para a produção, isso graças as inovações e evoluções dessas técnicas e tecnologias nos transportes e nos meios de comunicação, o que garante uma maior fluidez, como nos comandos e decisões gerenciais, e melhoram as redes, facilitando a logística (CORRÊA, 1991, p. 140). Daí então compreender o fato de determinadas empresas, como a Missiato de Bebidas Ltda, mesmo atuando num país como o Brasil de tamanho continental, terem seus parques industriais longe do mercado consumidor e ainda assim fazerem-se presentes, enquanto mercadorias.

Após a segunda guerra mundial e mais precisamente a partir dos anos 70 do século XX, incluindo nos chamados países periféricos, as técnicas de produção tornaram-se mais complexas e dinâmicas, tanto material quanto imaterialmente, auxiliadas pela circulação informacional nas tomadas de decisões, ordens de poder, controle de gestão e demanda de produção. É o chamado Meio Técnico-CientíficoInformacional de Milton Santos. Este afirma que:

Os objetos técnicos tendem a ser ao mesmo tempo técnicos e informacionais, já que, graças à extrema intencionalidade de sua produção e de sua localização, eles já surgem como informação; e, na verdade, a energia principal de seu funcionamento é também a informação. [...] a ciência e a tecnologia, junto com a informação, estão na própria base da produção, da utilização e do funcionamento do espaço e tendem a constituir o seu substrato (SANTOS, 2006, p. 159).

A informação tornou-se motor da produção no final do século XX. As grandes corporações, como afirma Corrêa (1991, p. 139), atuam praticamente em todo o planeta graças a fluidez informacional, garantindo gerencial e economicamente o controle de todas as etapas do processo de produção, a exemplo das indústrias chinesas. Entretanto, Corrêa (1991, p. 138) afirma que para garantir o 
controle da produção e a acumulação produtiva, as corporações assumem um elevado número de unidades produtivas e de serviços. A exemplo, tem-se:

[...] sede, centro de pesquisa e desenvolvimento, escritórios de compra de matérias-primas, depósitos, unidades fabris, escritórios de venda, unidades de prestação de serviços especializados, etc. Essa escala de operações resulta tanto dos investimentos criadores de novas unidades como da aquisição de empresas já existentes (CORRÊA, 1991, p.138).

No caso da Indústria Missiato de Bebidas Ltda, justificando sua ampla escala de operação (todos os estados do Brasil e em outros países), há o gerenciamento de determinadas unidades de serviços, duas de produção e duas de distribuição, além de uma equipe responsável pelo desenvolvimento de novos produtos e processos. Ou seja, o chamado centro de pesquisa e desenvolvimento - P e D (CORR̂EA, 2010, p. 23).

Os estudos sobre rede geográfica, mas particularmente sobre a rede urbana, tiveram forte influência da teoria das localidades centrais de Christaller (1966). Esta afirma que há uma hierarquia dentro da rede urbana, composta por localidades centrais e suas hinterlandias (área de atuação ou influência na oferta de bens e serviços). Contudo, apesar de importante ao entendimento da rede urbana, a referida teoria não se aplica mais a determinadas realidades, já que criada na primeira metade do século XX como modelo àquele contexto, logo desatualizada à evolução da rede. Dentre os principais motivos à desatualização estão: a complexa relação de deslocamento de pessoas no espaço, desfavorecendo a teoria de alcance espacial máximo e alcance espacial mínimo (Christaller, 1966), teoria esta que trata do consumo frequente ou não frequente de produtos, a partir do grau de centralidade e de funções centrais ou não centrais ofertadas; os transportes, que estão cada vez mais modernos e eficientes, o que facilita a circulação de mercadorias; a renda diferenciada da população, fazendo com que, mesmo em pequenas cidades, alguns se sobressaiam economicamente; a especialização da produção, promovendo maior autonomia dos centros locais; o crescente desenvolvimento tecnológico, dentre outros.

No ano de 2010, pela Universidade do Estado do Rio de Janeiro, Roberto Lobato Corrêa produziu um conjunto de esquemas gráficos geográficos intitulado "Esquemas Geo(gráficos)", descrevendo aspectos da organização espacial sob o foco de três sub-campos: a teoria geográfica, as redes geográficas - 
particularmente a rede urbana - e a organização interna da cidade. Dentre estes sub-campos, alguns exemplos simplificados de redes geográficas (Figura 1) e os padrões de interações espaciais em rede (Figura 2), fundamentais ao desenvolvimento deste trabalho.

a) Rede ferroviária

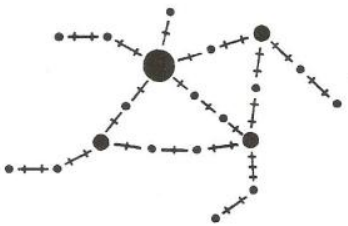

b) Bacia leiteira

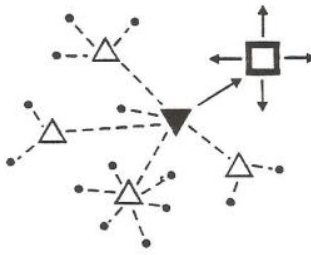

c) Corporação

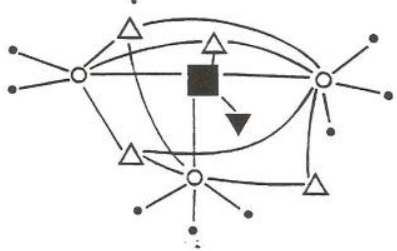

d) Rede urbana

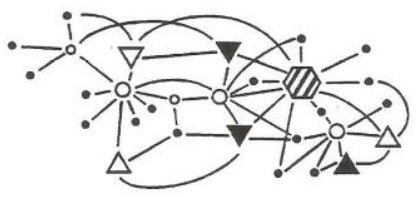

Organizado por: Roberto Lobato Corré 1999
Estação central

- Entroncamentos

- Paradas

$\rightleftarrows$ Trilhos

Figura 1. Redes Geográficas - exemplos simplificados.

Fonte: Esquemas Geo(Gráficos) - Corrêa (2010).

Os exemplos acima, em específico o da corporação, ajudam no entendimento da rede geográfica desenvolvida pela Missiato de Bebidas Ltda. De acordo com Corrêa (1991), a indústria adota um conjunto de unidades produtivas e de serviços que compõe sua estrutura e garante sua dinâmica de produção. Para a Missiato Ltda., este conjunto, análogo à corporação no referido esquema, condicionado ao modo de produção e articulado espacialmente, possui uma sede, um setor de pesquisa e desenvolvimento (sem estrutura física, mas presente nesta sede), uma filial e dois centros de 
distribuição. Todos esses componentes, somados aos diversos fluxos que compõem sua estrutura, formam uma rede geográfica específica que, baseado no "esquema" abaixo, corresponde ao tipo dendrítica. As razões à essa conclusão serão expostas no decorrer do presente artigo.

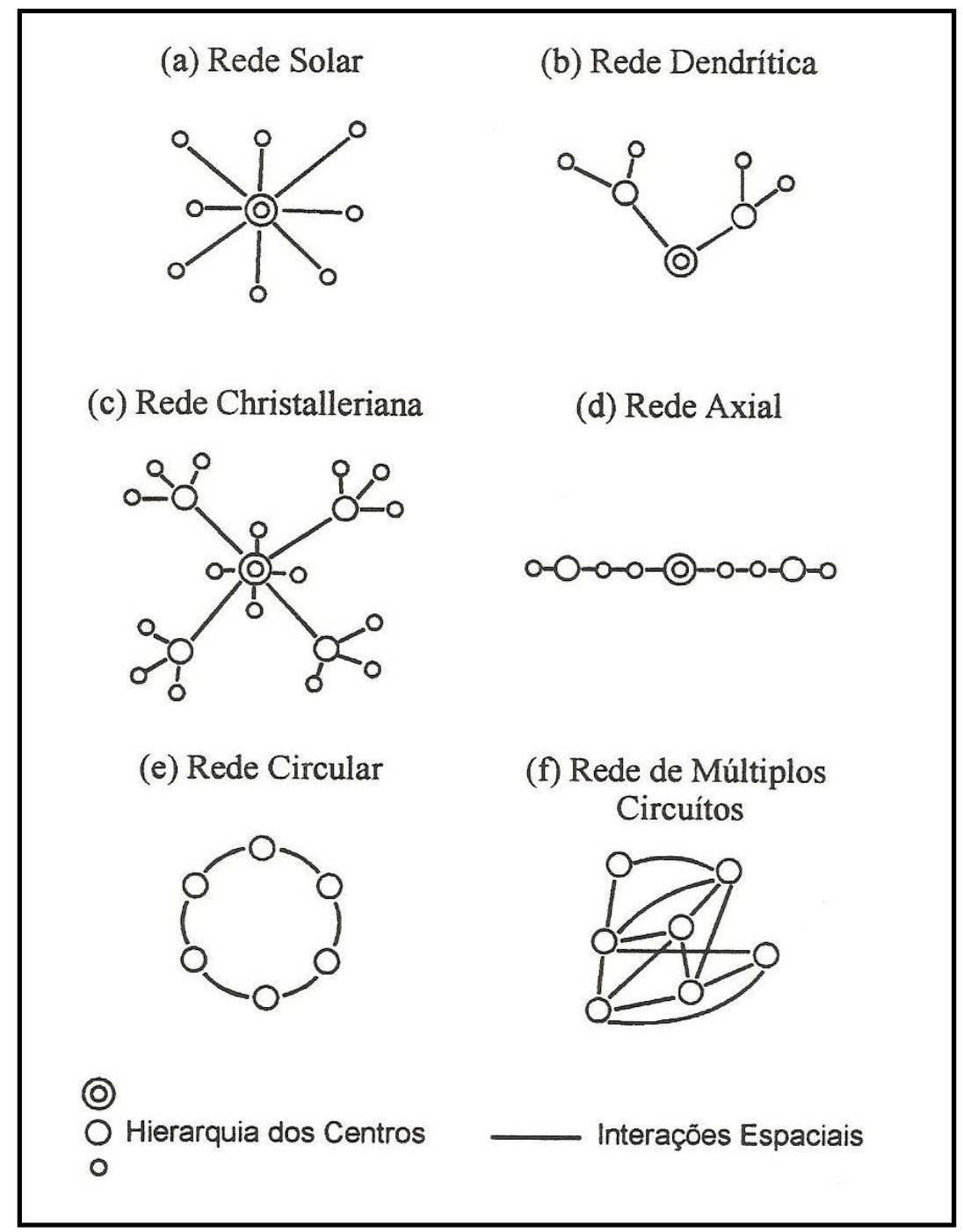

Figura 2. Padrões de interações espaciais em rede.

Fonte: Esquemas Geo(Gráficos) - Corrêa (2010).

Em suma, o levantamento apresentado, como os esquemas criados por Corrêa (2010), apresenta informações que foram essenciais à definição do tipo de rede e suas características da Indústria Missiato de Bebidas Ltda e auxiliou na construção do mapa de sua rede geográfica (Vide Mapa 1). 


\section{CARACTERIZAÇÃO DA INDÚSTRIA MISSIATO DE BEBIDAS LTDA}

A indústria de bebidas Missiato começou suas atividades na década de 1950 (Figura 3), na cidade de Santa Rita do Passa Quatro, interior paulista. Nesse período, segundo informações da própria indústria, o mercado nacional já consumia aguardente em quantidade expressiva, o que favoreceu sua implantação.

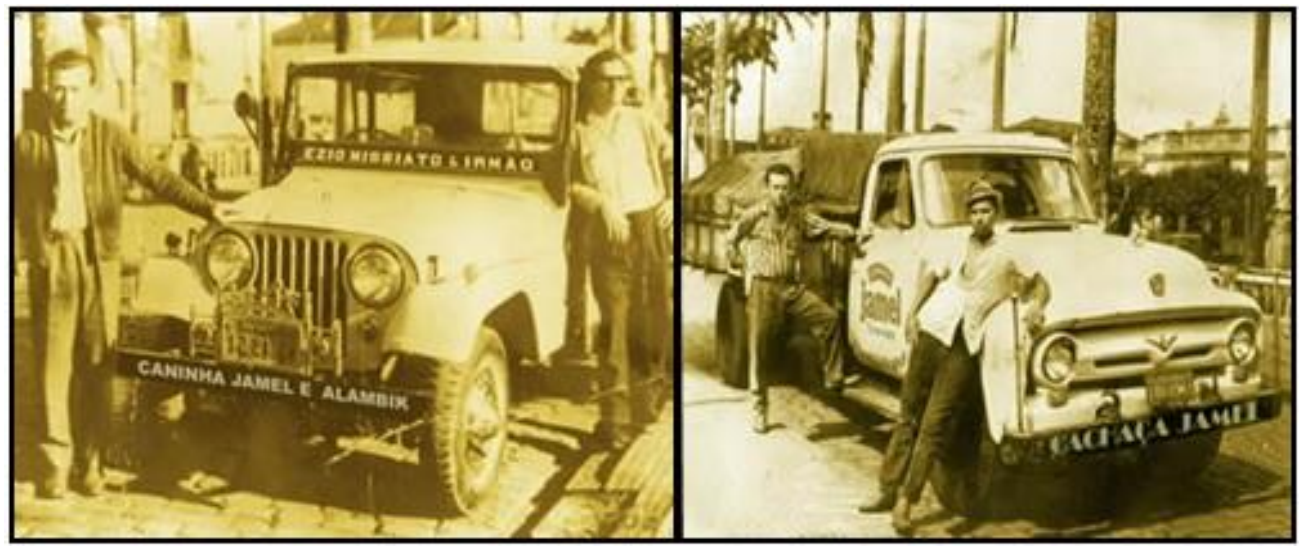

Figura 3. Circulação da cachaça Jamel.

Fonte: http://www.jamel.com.br/pt/historia/historia.php, 2014.

Em 1982, enquanto filial, a indústria instalou-se na região norte do Paraná, em Jandaia do Sul

(Figura 4), na perspectiva de uma produção em larga escala e dos benefícios advindo da mudança, como por exemplo mão de obra intensa e mercado consumidor crescente. Entretanto, com a ampliação do mercado, criou-se outra unidade de produção, inaugurada em 2008 na cidade de Anápolis-GO (Figura 5). Além desta última, um centro de distribuição em Porto Ferreira-SP e outro em ManausAM. São assim duas unidades de produção e dois centros de distribuição atendendo todos os estados do Brasil e outros países. 


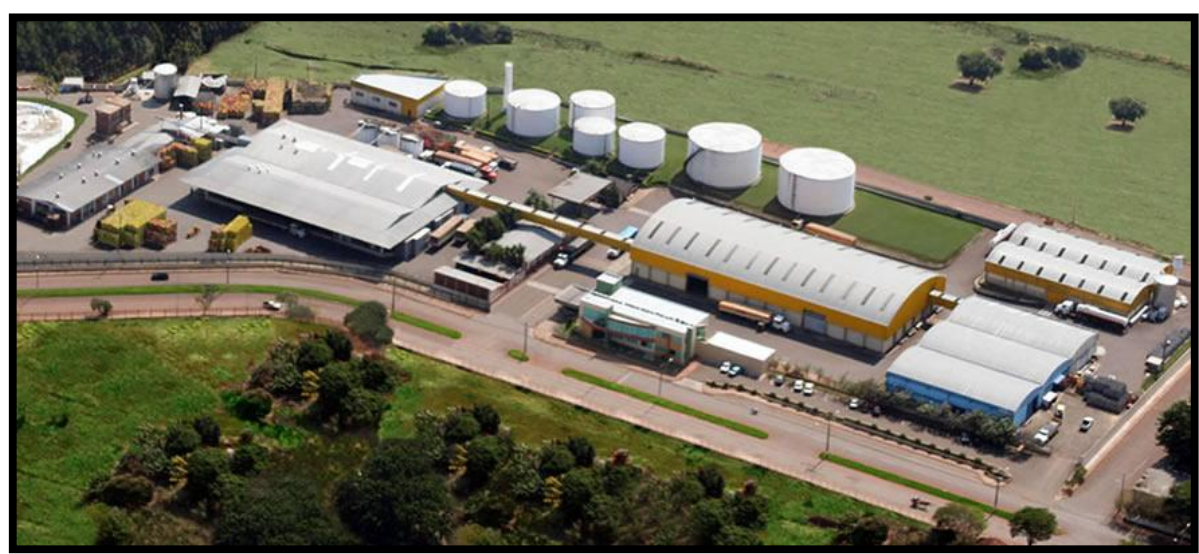

Figura 4. Unidade de produção em Jandaia do Sul-PR.

Fonte: http://www.jamel.com.br/pt/fabrica/fabrica_jan.php, 2014.

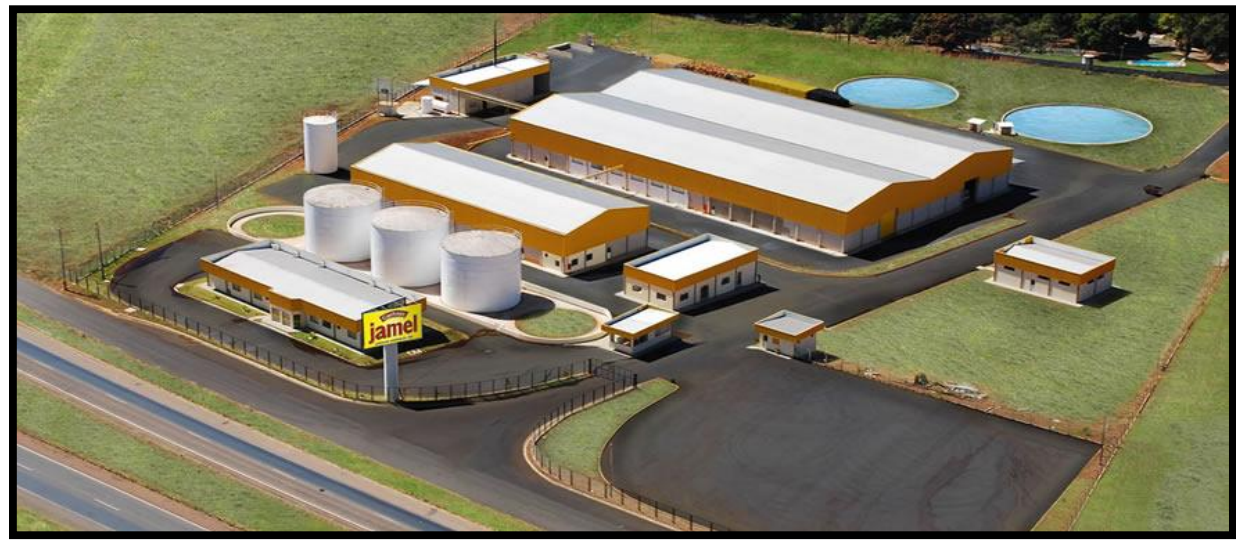

Figura 5. Unidade de produção em Anápolis-GO.

Fonte: http://www.jamel.com.br/pt/fabrica/fabrica_ana.php, 2014.

De acordo com Santos (2006), em monografia defendida pela Universidade Estadual de Londrina, a empresa, em seu início, denominada Ésio Missiato e irmãos (Armando e Arnaldo), comprava e vendia bebidas em geral no atacado e no varejo. A partir de 1974 passou a produzir e a comerciar bebidas, sob a denominação de Missiato S/A Indústria e Comércio. Em 1982, iniciou atividade em Jandaia do Sul-PR sob forma de filial e em 1994 passou de S/A para Ltda, denominando-se Missiato Indústria e Comércio Ltda. Com o crescimento em especial da filial, em 1997 seu faturamento já era maior do que o da sede, foi quando houve uma cisão de seus sócios, seguindo-se independente como Indústria Missiato de Bebidas Ltda, mantendo-se a marca da cachaça Jamel. 
Segundo o Diário do Comércio e Indústria, com dados de 2013, a empresa, com sede em Jandaia do Sul-PR, produz anualmente 25 milhões de litros de cachaça, sendo 5\% destinados à exportação, e espera elevar em 3\% o volume exportado.

A Indústria Missiato tem seu parque industrial (matriz) instalado na Av. Anunciato Sonni, nº 3.040, em Jandaia do Sul-PR, possuindo 8.000m de área construída. Sua filial localiza-se na rodovia BR153 no Km 47 em Anápolis-GO, contando com modernos equipamentos de produção de bebidas destiladas, álcool, produtos saneantes domissanitários (destinados à higienização/desinfecção domiciliar) e fabricação de embalagens.

O parque industrial passa por constantes melhorias à implementação de novas tecnologias de forma pioneira, agilizando o processo produtivo e consequentemente contribuindo para o desenvolvimento da indústria.

Dentre a produção de bebidas destiladas (Figura 6) está a cachaça Jamel, muito conhecida no sul do país, com produção em larga escala que levou Jandaia do Sul a figurar como um importante polo nacional da cachaça. Além desta, a Jamel Ouro, a Caninha Missiato, a Cachaça Camelinho e 0 Garrafão. Entretanto, buscando aperfeiçoamento, elaborou-se novos produtos: Whisky, batizado de Gran Par, Vodkas Romanoff e Miscov de produção com destilados de cereais, além de Rum, Vinho e outros. 


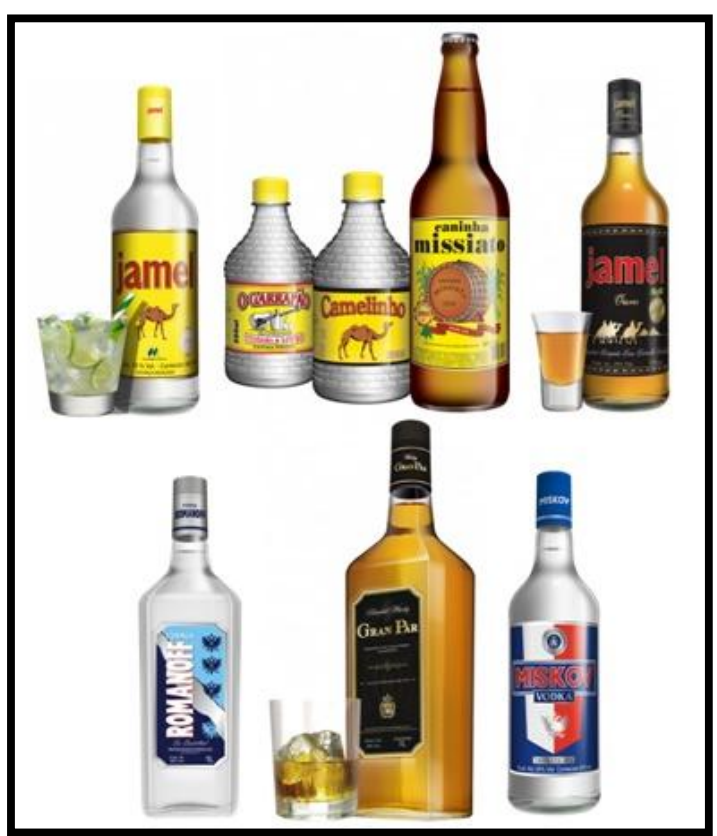

Figura 6. Parte da produção da Missiato.

Fonte: http://www.jamel.com.br/pt/principal.php, 2014.

Segundo a empresa, a sede conta hoje com 180 colaboradores diretos e gera 500 empregos indiretos.

Possui também atividades sociais como missa mensal para funcionários e familiares, festa junina, dia das crianças e confraternização, além de área de lazer: sala de ginástica, quadra poliesportiva, campo de futebol, bocha e outras atividades.

\section{ANÁLISE DOS DADOS COLETADOS}

Do levantamento teórico sobre o tema e de sua problematização, além das pesquisas junto ao site da empresa, jornais e trabalhos acadêmicos, bem como das informações coletadas via ofício à Missiato de Bebidas Ltda, foi possível obter uma série de dados sobre a dinâmica de trabalho desta indústria, permitindo-se assim a construção de sua rede geográfica de atuação no Brasil, em especial no que tange a logística de distribuição e circulação de mercadorias. 
Por se tratar de uma empresa de ampla atuação a nível nacional, torna-se necessário um aparato de ferramentas e de mecanismos que possibilitem esse fim (CORRÊAA, 1991). No caso específico da Missiato, foram constatadas duas unidades de produção, uma em Jandaia do sul-PR, que é a sede/matriz, e outra em Anápolis-GO. Além dessas unidades, dois centros de distribuição, um em Porto Ferreira, no estado de São Paulo, e outro em Manaus, no Amazonas, e um centro de pesquisa e desenvolvimento localizado na matriz. Entretanto, as mercadorias partem não somente dos centros de distribuição, mas também das unidades de produção, com base na proximidade destas ao específico mercado consumidor.

A hierarquia de gestão e de poder da Missiato segue da matriz, centro produtor, disseminador e gestor de informações, de mercadorias, de tecnologia, de capital e de praticamente todo o processo produtivo às demais unidades. Entretanto, cada unidade possui um gerente administrativo, que mantém relativa autonomia às intempéries cotidianas da Indústria, porém submissos à Matriz. E apesar da Missiato possuir um grupo responsável pelo desenvolvimento de novos produtos e processos, o chamado centro de pesquisa e desenvolvimento - P e D (CORRÊAA, 2010, p. 23), a indústria não o considera como tal, segundo dados adquiridos junto ao ofício. Entretanto, é de lá que surgem as inovações e melhorias no processo produtivo e nas mercadorias.

Abaixo segue o detalhamento das informações (questionamentos e respostas) impetradas via ofício (Quadro 1) junto a Missiato, que, somadas aos demais dados, ajudou no mapeamento de sua rede geográfica.

\begin{tabular}{|c|c|}
\hline Questionamentos & Respostas da empresa \\
\hline $\begin{array}{l}\text { Como funciona e onde se localiza o centro de distribuição de } \\
\text { bebidas da Jamel para o Norte, Nordeste, Centro Oeste, Sul e } \\
\text { Sudeste do Brasil? } \\
\text { Qual(is) a(s) região(ões) de maior demanda? }\end{array}$ & $\begin{array}{l}\text { Norte e Nordeste é distribuido pelo centro de distribuição de } \\
\text { Manaus-AM; região Centro Oeste pela filial Anápolis-GO; Sul } \\
\text { e Sudeste pela Matriz e pelo centro de distribuição de Porto } \\
\text { Ferreira-SP. } \\
\text { A maior demanda é da região Sul e Sudeste. }\end{array}$ \\
\hline $\begin{array}{l}\text { Como é feito o transporte das mercadorias? de caminhão, } \\
\text { avião, navio... Por empresa terceirizada? }\end{array}$ & $\begin{array}{l}\text { O transporte dos produtos é realizado com caminhões de frota } \\
\text { própria e terceirizados para o mercado interno e navio para } \\
\text { exportação. }\end{array}$ \\
\hline $\begin{array}{l}\text { A Jamel tem algum centro de pesquisa, por exemplo para } \\
\text { identificar perfil de consumidor, visando melhorar ou ampliar } \\
\text { produção? se tem, onde se localiza? }\end{array}$ & $\begin{array}{l}\text { Não, trabalha apenas com equipe interna de desenvolvimento } \\
\text { de novos produtos e processos, localizado na Matriz. }\end{array}$ \\
\hline
\end{tabular}




\begin{tabular}{|l|l|}
\hline $\begin{array}{l}\text { O pedido de mercadoria dos clientes (via telefone, internet ou } \\
\text { fax?) é feito diretamente com a Missiato Ltda ou para um } \\
\text { representante da empresa? Caso o pedido seja feito para um } \\
\text { representante, a mercadoria é entregue para este e o mesmo a } \\
\text { redireciona ao cliente ou é entregue diretamente para o cliente? }\end{array}$ & $\begin{array}{l}\text { Direto via deposito comercial e via representantes, porém o } \\
\text { produto é entregue diretamente ao cliente. }\end{array}$ \\
\hline $\begin{array}{l}\text { Seria possível informar o faturamento anual da empresa ou ao } \\
\text { menos de 2013? }\end{array}$ & Dados não divulgados. \\
\hline $\begin{array}{l}\text { Existe alguma relação entre a Indústria Missiato de Bebidas } \\
\text { Ltda/Jamel com a Missiato Indústria e Comércio Ltda, da } \\
\text { conhecida Cachaça 61? }\end{array}$ & $\begin{array}{l}\text { No inicio das atividades era uma sociedade denominada Ésio } \\
\text { sócios ficando a Missiato Jandaia como Matriz. Posteriormente } \\
\text { constituiria suas filiais em Goiás, Porto Ferreira e em Manaus- } \\
\text { AM. }\end{array}$ \\
\hline
\end{tabular}

Quadro 1. Questionamentos e respostas do ofício.

Fonte: elaborado pelos autores, 2014.

Os dados mostram que a proximidade de localização do centro distribuidor e/ou produtor ao mercado consumidor comanda a distribuição e circulação de mercadorias. Apontam também as regiões Sul e Suldeste como as maiores consumidoras dos bens produzidos pela Missiato, portanto com as maiores demandas.

Quiçá por baixo investimento, dificuldades de logística, identidade cultural e/ou existência de grandes concorrentes nas regiões mais afastadas do Sul e Sudeste brasileiro, a maior demanda de produtos venha se concentrar nestas duas regiões. Entretanto, a Missiato atua também em cidades bastante distantes do Sul, como da região Norte, a partir do centro de distribuição de Manaus e/ou representantes de vendas da região, que recebem os pedidos de mercadorias dos clientes e repassam para a indústria. Entretanto, se o referido centro de distribuição não tiver estoque para atender ao cliente, a mercadoria é enviada diretamente da segunda unidade mais próxima ao destino final, desde que a negociação não seja um mal investimento à Indústria.

Segundo a Missiato, a empresa não possui centro de pesquisa, como já exposto, mas afirma a existência de uma equipe interna de desenvolvimento de novos produtos e processos, o que traduz-se, segundo Corrêa (2010, p.23), num centro de pesquisa e desenvolvimento - P e D, essencial na conquista de novos mercados, de mais eficiência na produção e de novos consumidores. 
A distribuição e circulação de mercadorias da Missiato, a nível nacional, é feita por caminhões terceirizados e/ou próprios, um transporte caro se comparado ao ferroviário, principalmente num país de tamanho continental. Segundo Corrêa (1991), a evolução tecnológica dos sistemas de transporte favoreceu a comunicação e "diminuiu as distâncias" entre os espaços. Contudo, estrategicamente precisa-se escolher o "transporte certo" às intempéries do modo de produção capitalista, quando há opção, principalmente em grandes territórios. Ou seja, mesmo com essa evolução, não se pode descartar o fator "eficiência". Em outras palavras, "melhor transporte" e "melhor preço de uso", o que se traduz em segurança, praticidade, capacidade (quantidade de produto transportado de uma só vez) e capital empregado, do ponto de vista quantitativo.

No que tange às transformações técnicas, a melhoria dos sistemas rodoviário, ferroviário, aeroviário e dos objetos e instrumentos de navegação marítima e hidroviária, tornam o transporte mais seguro e mais rápido, aumentando a fluidez potencial do território (exigência e condição do sistema produtivo globalizado) (PEREIRA, 2009, p. 124).

Infelizmente, o transporte ferroviário brasileiro ainda está aquém de satisfazer as necessidades da produção industrial nacional e vir a substituir o rodoviário em termos de importância. Isso mostra que, no Brasil, de acordo com análise dos dados da Confederação Nacional dos Transportes do ano de 2013, a rede ferroviária ainda é ineficiente e inadequada as necessidades da produção e integração do território nacional.

A malha ferroviária brasileira alcançou, em 2012, $30.129 \mathrm{~km}$ de extensão, incluindo trens urbanos de passageiros. O valor é inferior ao pico observado no início da década de 1960, quando a quilometragem total das ferrovias chegou a $38.287 \mathrm{~km}$, mas é superior ao existente na década de 1980, quando a malha existente alcançou pouco mais de $28.942 \mathrm{~km}$. Atualmente, a densidade da malha ferroviária brasileira é de pouco mais de $3,3 \mathrm{~km}$ de linhas férreas por mil $\mathrm{km}$ de território (CNT, 2013, p. 25).

Além de passar por retrocessos, a partir de 1960 (Gráfico 1), no ano de 2013 não se chegava a $4 \mathrm{~km}$ de linhas férreas construídas por mil $\mathrm{km}$ de território, o que comprova a ineficiência da ferrovia brasileira diante das exigências da produção industrial nacional. Além do que, estamos falando de um país com mais de 8 milhões de $\mathrm{km}^{2}$ de território (IBGE, 2014), desconsiderando os espaços inóspitos. 


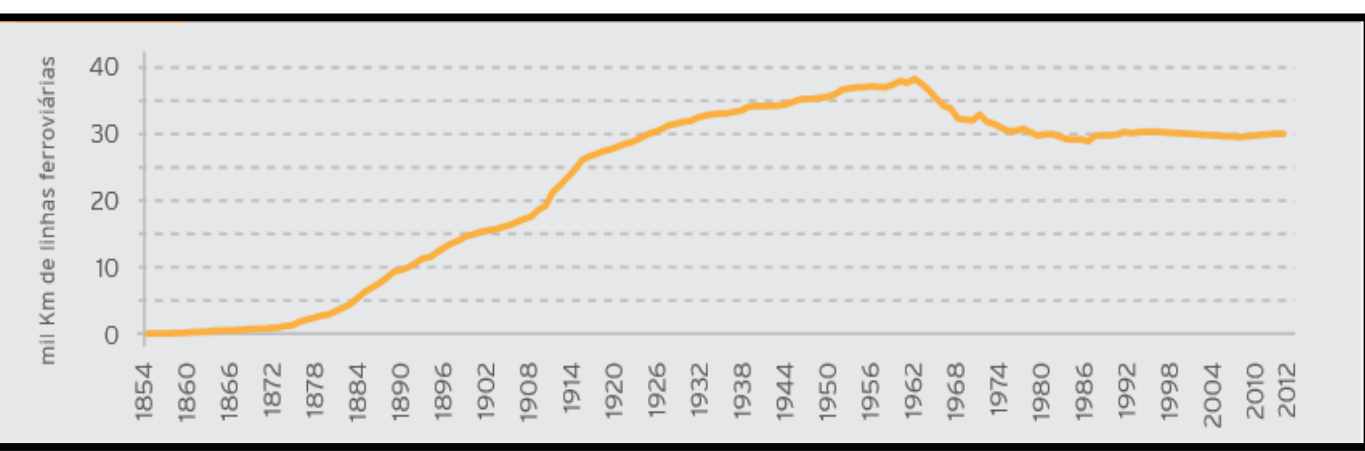

Figura 7. Extensão da malha ferroviária nacional (1854 a 2012).

Fonte: Elaboração CNT com dados do IBGE, da Pesquisa de CNT de Ferrovias 2011 e da ANTT (agosto de 2012). *Até 1993 os dados se referem a série histórica do IBGE. Os anos seguintes foram estimados com base nos dados das Pesquisas Ferroviárias da CNT de 2006, 2009 e 2011 e da ANTT (agosto de 2012).

Segundo a Missiato, o abastecimento dos centros de distribuição segue da unidade fabril mais próxima, da matriz ou da filial em Anápolis-GO. Contudo, quando verificado estoque e constatado que na unidade mais próxima há indisponibilidade de mercadoria para o abastecimento, o mesmo segue de caminhões da segunda fábrica. É o que no mapa da página seguinte (Mapa 1) corresponde ao chamado "abastecimento secundário". Porém, apesar de usar caminhões, mesmo sendo caro, a indústria dificilmente deixa de abastecer seus centros de distribuição, porque entende ser algo essencial à circulação de mercadorias e que isso implica em ganho de capital.

Conforme os dados apresentados, segue o mapa com a rede geográfica nacional da Indústria Missiato de Bebidas Ltda (Mapa 1). 


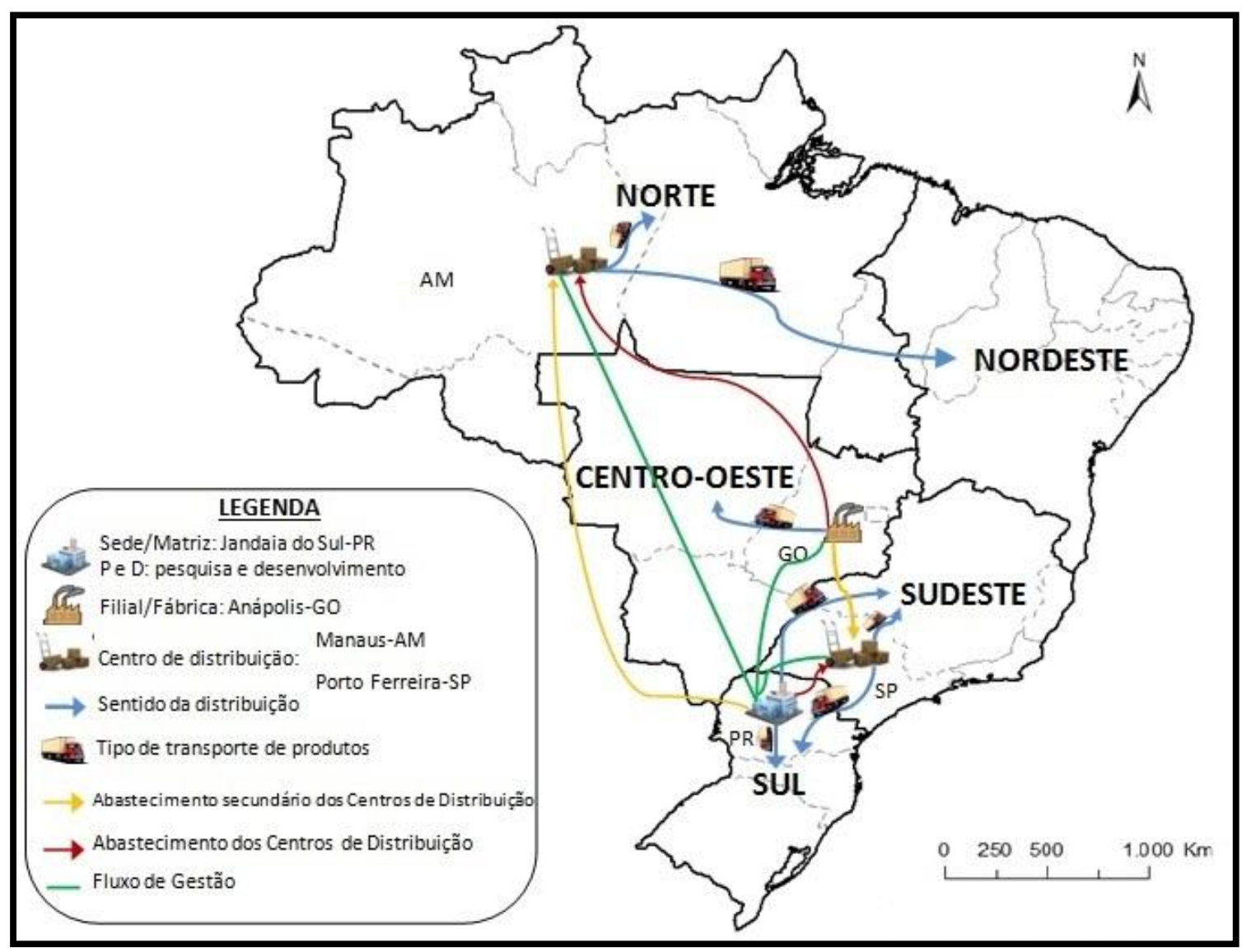

Mapa 1. Rede geográfica nacional da Indústria Missiato de Bebidas Ltda.

Fonte: elaborado pelos autores, 2014.

De acordo com o mapa, o padrão nacional de interação espacial em rede que mais se adéqua ao estabelecido pela Indústria Missiato de Bebidas Ltda é do tipo dendrítico, conforme Corrêa (2010, 2011). Entretanto, dos arranjos espaciais apontados por Lobato, do tipo solar, dendrítico, christalleriana, axial, circular e de múltiplos circuitos, o tipo dendrítico é um dos mais simples, derivado do período colonial. Nas palavras do próprio autor (2011, p. 206-207), "a rede dendrítica é de origem colonial e tem a sua forma análoga à de uma rede fluvial. A principal cidade está excentricamente localizada próxima à foz do rio que drena a rede". Basicamente, toda a gestão e grande parte das interações espaciais da Missiato partem da matriz, que seria como a cidade portuária. Apesar disto, a rede se mostra eficiente às necessidades da industria, particularmente de logística, bem como na produção e reprodução de capital, projetando-a como uma das principais produtoras em seu ramo no país. A indústria conduz então o fator proximidade como primordial em sua dinâmica e não apresenta interações espaciais multidirecionadas, que é característica do padrão de múltiplos circuitos (típico de grandes corporações). 
Quanto mais complexa a rede geográfica (no sistema capitalista), estando esta dentro de uma intensa área industrial e urbanizada, maior probabilidade ela tem de constituir um padrão de interação espacial de múltiplos circuitos. Nas palavras de Lobato Corrêa,

\footnotetext{
As redes de múltiplos circuitos constituem o tipo mais complexo, resultado de uma mudança face a redes menos complexas. São típicas de áreas industrializadas, com elevado grau de urbanização e com muito significativa divisão territorial do trabalho. Os centros de rede diferenciam-se segundo a posição na hierarquia de lugares centrais e segundo as especializações produtivas que apresentam. Centros de mesma hierarquia podem apresentar especializações distintas, do mesmo modo que centros com a mesma especialização produtiva podem situar-se em níveis distintos da hierarquia urbana. As interações espaciais são, assim, multidirecionadas e não mais definidas pelo alcance espacial típico da distribuição varejista, mas por outras lógicas: a distância tem um sentido diferente em uma rede de múltiplos circuitos. As interações espaciais se entrecruzam, não se caracterizando por padrões sistemáticos, próprios das redes anteriormente descritas (CORRÊA, 2011, p. 207).
}

A Missiato não possui essencialmente essa complexidade em sua rede de distribuição e circulação de mercadoria, uma vez que a maioria de suas interações espaciais não são multidirecionadas, mas bastante apegadas ao fator proximidade. Apenas sua gestão aproxima-se de um padrão de múltiplos circuitos, onde as informações circulam com maior fluidez no espaço, devido aos avanços nas tecnologias de comunicação, mas centralizada sob a matriz. E nem toda sua área de abrangência possui um elevado grau de urbanização e de industrialização.

\section{CONSIDERAÇÕES FINAIS}

A Indústria Missiato de Bebidas Ltda está no mercado desde o início da segunda metade do século XX, passou por várias transformações, incluindo um processo de cisão e tem se desenvolvido desde então. Hoje a indústria é considerada uma das principais em seu ramo, no que se refere à produção e distribuição de mercadoria a nível Brasil, mas possui um padrão de interação espacial em rede do tipo dendrítico, um arranjo de origem do período colonial e bem distante da realidade de um padrão de múltiplos circuitos, típico de áreas industriais e característico em grandes corporações que possuem um alto grau de complexidade em seus sistemas (CORREA A, 2010, 2011). Atualmente a Missiato exporta parte de sua produção através de navios e vem crescendo no mercado internacional, o que futuramente poderá se caracterizar em um novo arranjo espacial mais dinâmico e complexo. 
A estrutura geral da indústria de atendimento ao mercado, formada por sua sede, uma filial de produção, uma equipe responsável pelo desenvolvimento e melhoramento dos produtos e dois centros de distribuição - um na região Norte e outro na região Sudeste, passa constantemente por melhorias tecnológicas afim de ampliar e melhorar a produção, resultando em maior lucro e reduzindo os possíveis impactos que poderiam diminuir seu ritmo de crescimento. Apesar disto, possui forte dependência do transporte rodoviário à circulação das mercadorias (uso de caminhão de frota própria e terceirizada, algo que se torna oneroso em um país de tamanho continental), não apenas por escolha, mas pela limitada disposição de outros tipos de transporte, como o ferroviário que atende apenas poucas cidades/estados, segundo o gráfico da CNT sobre a extensão da malha ferroviária nacional entre 1854 e 2012. Contudo, a importância atribuída pela Missiato ao fator "proximidade" entre mercado consumidor e centro de distribuição auxilia na minimização dos gastos com o transporte das mercadorias, assim como em seu tempo de entrega, acarretando um aumento em sua margem de lucro. A exemplo, a distribuição à região Nordeste, que é realizada pelo centro de distribuição de Manaus-AM ou pela filial mais próxima, em caso de indisponibilidade de mercadoria no CD.

Em suma, apesar de possuir uma rede geográfica derivada ainda do período colonial, a indústria tem eficácia em sua produção e circulação de mercadorias e está se consolidando como uma das principais produtoras em seu ramo à nível nacional.

A presente análise baseou-se apenas na atuação nacional da referida indústria, desconsiderando então seus dados de exportação, o que poderia mudar o quadro exposto. Contudo, expõe uma visão dedicada sobre sua rede geográfica de conjuntura atual, facilitando seu entendimento e auxiliando futuros trabalhos.

\section{REFERÊNCIAS}

Confederação Nacional do Transporte (CNT). Transporte e economia: o sistema ferroviário brasileiro. Brasília: CNT, 2013. Disponível em: < http://www.cnt.org.br/Imagens\%20CNT/PDFs\%20CNT/Transporte_e_economia__0_sistema_ferroviario_brasileiro_.pdf $>$. Acesso em 09 ago. 2014. 
CORREAA, R. Lobato. Princípios de Centralidade. Curso de férias para professores de geografia do ensino médio. Ministério do Planejamento e Coordenação Geral, Fundação IBGE, p. 132-141, 1970.

Concentração bancária e os centros de gestão do território. R. bras. Geogr., Rio de Janeiro, v. 51, n. 2, p.17-32, abr./jun. 1989.

Corporação e Espaço: uma nota. R. bras. Geogr., Rio de Janeiro, v.53, n.1, p.137-145, jan./mar. 1991.

Repensando a teoria das localidades centrais. In: SANTOS, M (Org.). Novos Rumos da Geografa Brasileira. São Paulo: Hucitec, 1982. p.50-65.

DIAS, L. Christina. Os sentidos da rede: notas para discussão. In: DIAS, L. \& SILVEIRA, R. L. L. (Orgs.). Redes, sociedades e territórios. Santa Cruz do Sul: Edunisc, 2005. p.11-28.

Esquemas Geo(Gráficos). NEPEC 4, Rio de Janeiro, ago. 2010.

Redes Geográficas: reflexões sobre um tema persistente. Cidades, Presidente Prudente. v. 9, n. 16. p.199-218, jul./dez. 2011.

FRESCA, T. Maria. A rede do norte do Paraná. Londrina: Eduel, 2004.

FRESCA, T. Maria. Centros locais e pequenas cidades: diferenças necessárias. Mercator, Fortaleza. v. 9, n. 20. p.75-81, set./dez. 2010.

IBGE, Instituto Brasileiro de Geografia e Estatística. Disponível em: < http://brasilemsintese.ibge.gov.br/territorio/dadosgeograficos>. Acesso em: 09 ago. 2014.

INDUSTRIA Missiato de Bebidas Ltda. Disponível em: < http://www.jamel.com.br/pt/principal.php>. Acesso em: 30 jun. 2014.

PEREIRA, M. F. V. Redes, sistemas de transportes e as novas dinâmicas do território no período atual: notas sobre o caso brasileiro. Sociedade \& Natureza, Uberlândia. v. 21, n. 1. p.121-129, Abr. 2009.

QUINTELA, A. Paula; Diário do Comércio \& Indústria. Cachaça envelhecida e caipirinha "ice" atraem novos consumidores. SEBRAE, 2003. Disponível em: $\left\langle\right.$ http://www.sebrae-sc.com.br/ideais/default.asp?vedtexto $=4696 \&^{\wedge \wedge}>$. Acesso em: 28 jun. 2014.

RIBEIRO, M. A. C. A complexidade da rede urbana amazônica: três dimensões de análise. Tese (Doutorado). Universidade Federal do Rio de Janeiro, Rio de Janeiro, 1998.

SANTOS, Milton. A Natureza do Espaço: espaço e tempo, razão e emoção. $4^{\mathrm{a}}$ ed. São Paulo: Edusp, 2006. 259 p.

SANTOS, Milton. 0 país distorcido: o Brasil, a globalização e a cidadania. São Paulo: Publifolha, 2002.

SANTOS, R. Félix dos. A indústria cachaceira no Brasil atual: um estudo comparativo entre a CIA. Müller de Bebidas (Caninha 51) e a Indústria Missiato de Bebidas Ltda (Caninha Jamel). Monografia (Graduação). Universidade Estadual de Londrina. Londrina, 2006. Disponível em:

<http://www.geo.uel.br/tcc/031_aindustriacachaceiranobrasilatualumestudocomparativoentreaciamullerdebebidascaninha5 1eaindustriamissiatodebebidasltdacaninhajamel_2006.pdf.pdf >. Acesso em: 02 jul. 2014. 